\title{
Avaliação de Impactos Ambientais: redefinindo a inovação tecnológica'
}

Thales Novaes de Andrade ${ }^{2}$

\section{Resumo}

A inovação tecnológica possui um arcabouço gerencial sofisticado, e os administradores científicos precisam integrar diferentes áreas de pesquisa e desenvolvimento. A avaliação de impactos torna-se cada vez mais relevante em diversas instituições de pesquisa, norteando as formas de financiamento e implementação de projetos. Nesse contexto, as variáveis ambientais tornam-se extremamente relevantes, e seus impactos precisam ser levados em conta nos processos de avaliação de tecnologias.

Palavras-chave: inovação tecnológica, avaliação de impactos, meio ambiente, Embrapa.

\section{Introdução}

\begin{abstract}
A tualmente, a inovação tecnológica precisa se submeter a práticas gerenciais sofisticadas, e os policy-makers precisam dar coerência e integração às diferentes áreas de pesquisa, desenvolvimento e difusão tecnológica. Na esteira dessa tendência à burocratização das práticas científicas, muitos autores consideram as inovações organizacionais tão relevantes quanto as inovações tecnológicas, de modo que as primeiras são muitas vezes encarregadas em liderar a implementação dessas últimas (SANIDAS, 2004).
\end{abstract}

1 Esse trabalho é parte de uma pesquisa sobre gestão da inovação tecnológica que obteve financiamento do CNPq.

2 Doutor em Ciências Sociais pela Unicamp, docente do Departamento de Ciências Sociais da UFSCar e editor do periódico Teoria \& Pesquisa: revista de Ciências Sociais. Trabalha no campo dos estudos sociais da ciência e com pesquisas e na área ambiental. 


\section{Avaliação de impactos ambientais: redefinindo a inovação tecnológica}

Thales Novaes de Andrade

A pesquisa científica e tecnológica está submetida a parâmetros organizacionais mais impositivos, e o uso recorrente de metodologias gerenciais, como planejamento estratégico e identificação de prioridades, tem significado uma intervenção crescente sobre a agenda dos especialistas em diversas instituições (DAGNINO, 2007).

Uma das principais inovações organizacionais que emergiram recentemente em diversos ambientes de pesquisa científica e tecnológica foram as metodologias de avaliação de impactos tecnológicos (ZACKIEWICZ, 2003).

O desenvolvimento técnico deve submeter-se às novas modalidades de gestão e aos imperativos do processo produtivo. Segundo Zackiewicz, esse controle externo da ciência e tecnologia remonta a algumas décadas, implicando no fortalecimento das práticas de avaliação.

As práticas da escola de forecasting foram incentivadas pelos esforços dos governos em legislar sobre a ciência - especialmente sobre a custosa big science - e produzir accountability. Embora ainda sob perspectivas bastante diferentes, a partir do pós-guerra tanto a avaliação (externa) das atividades científicas quanto a previsão de seus avanços passaram a ser cada vez mais tratados por métodos com fortes influências da teoria econômica. A ciência, cada vez mais, precisava provar quantitativamente sua utilidade (ZACKIEWICZ, 2003: 196-7).

Nas últimas décadas os condicionantes ambientais tornaram-se extremamente relevantes nas avaliações de tecnologias, devido à sensibilização da discussão sobre os riscos e as controvérsias científicas. Ciência e tecnologia deixaram de ser parâmetros de avanço e confiabilidade, sendo vistas com reservas principalmente em relação aos seus efeitos ambientais (BECK, 1992).

Isso ocasionou uma atenção crescente em relação aos impactos ambientais, que precisam necessariamente ser levados em consideração nos processos de avaliação de tecnologias (BIN, 2004; ÁVILA et al., 2005).

O interesse do presente artigo consiste em discutir do ponto de vista sociológico como as atividades de inovação tecnológica es- 
tão sofrendo os efeitos da implementação de avaliação de impactos ambientais. Optou-se por realizar um estudo de caso na Empresa Brasileira de Pesquisa Agropecuária (Embrapa) para discutir como a avaliação dos impactos ambientais está modificando a prática inovativa dos pesquisadores seniors e também os mais novos que adentram à Empresa. Nos últimos anos foi desenvolvido nessa empresa o sistema Ambitec, uma ferramenta gerencial que implica na sistematização de indicadores que avaliam diversos impactos de tecnologias desenvolvidas e implementadas pela Embrapa, e no qual as variáveis ambientais são fundamentais.

Nessa pesquisa foram analisados documentos internos da Embrapa e conduzidas entrevistas semiestruturadas com pesquisadores de duas unidades: Embrapa Sudeste, sediada em São Carlos (SP) e a Embrapa Meio Ambiente de Jaguariúna (SP).

Através da análise desse material foi possível detectar as tensões e problemas relacionados à implementação de ferramentas de avaliação de impactos ambientais junto às atividades de inovação tecnológica no setor agropecuário.

\section{Avaliação de impactos tecnológicos e inovação}

A partir dos anos 80 , a problemática da avaliação tecnológica (technological assessment) se torna imperativa para as instituições de pesquisa. Não é mais possível financiar projetos tecnológicos e de inovação sem incorporar metodologias de avaliação que estabeleçam parâmetros de desempenho e eficácia dos projetos. Tem-se um "alargamento" do sistema de revisão por pares, de modo que agentes situados para além do círculo institucional mais próximo podem interferir nos mecanismos de seletividade dos projetos.

A avaliação continuada de programas e a preocupação com os impactos das tecnologias em suas mais diferentes acepções passam a constituir uma necessidade institucional incontornável, que solicita um considerável esforço para definição de variáveis e critérios metodológicos (FAHRENKROG et al., 2002). Policy makers, 


\section{Avaliação de impactos ambientais: redefinindo a inovação tecnológica}

Thales Novaes de Andrade

gestores e técnicos necessitam trabalhar coletivamente para estabelecer ferramentas de monitoramento e avaliação para implantação de projetos tecnológicos.

Segundo especialistas da área de metodologias de avaliação, parâmetros meramente quantitativos não são mais suficientes para se atestar a viabilidade de projetos tecnológicos. De acordo com um relatório da União Europeia, além de desenvolver diversas metodologias de avaliação de programas de pesquisa, os policy makers têm que procurar inserir também outros grupos de interesse no processo avaliativo e o estabelecimento de uma agenda política mais abrangente (FAHRENKROG et al., 2002).

A relação difícil entre pesquisa acadêmica e de inovação é um tema recorrente nas avaliações de programas tecnológicos. Ao discutirem casos de programas tecnológicos europeus, Callon et al. (1995) identificam neles uma grande dicotomia à pesquisa acadêmica, que tenderia a obedecer uma lógica autônoma dada pelos pesquisadores (cientistas e técnicos) e centrada na produção de conhecimentos teóricos; e a pesquisa aplicada, que se submeteria a uma lógica heterônoma ditada pelas empresas e marcada pela indução de inovações tecnológicas.

Para os autores, a avaliação tecnológica conduzida pelo Estado deveria transcender tanto o modelo acadêmico quanto o de inovação. Faz-se hoje necessário conciliar interesses econômicos com a lógica científica, e com isso construir ferramentas de avaliação que organizem as atividades técnicas e inovativas em forma de redes.

A partir dos anos 90 essa perspectiva se intensificou, de modo que governos e empresas passaram a defender a mensuração quantitativa e qualitativa da inovação, justificada pela necessidade de se enquadrar a pesquisa tecnológica dentro de um maior controle gerencial (SALLES FILHO et al., 2000).

Ao se considerar a gerência da $P \& D$ e a criação de indicadores para o sucesso inovativo, a avaliação da ciência, tecnologia $e$ inovação se enquadra à nova lógica de $\mathrm{P} \& \mathrm{D}$. Isso significa que as transformações na configuração da CT\&I se refletem no modo como se avaliam seus resultados: as metodologias avaliativas se transformam em mecanismos que embasam a tomada de decisões estratégicas no âmbito dos sistemas de inovação. 
Segundo Zackiewicz (2003), assiste-se à convergência entre as tradições de avaliação interna (revisão por pares) e externa (governo, avaliadores profissionais, órgãos de financiamento, etc.), e a emergência de uma nova gestão, que exige indicadores de desempenho e de programação das instituições de $\mathrm{P} \& \mathrm{D}$, e a busca por meios efetivos que associem produção científica e desempenho.

Nos anos 90, as atividades de avaliação de impactos tecnológicos tiveram que incorporar certos temas sociais que antes eram tangenciais nas instituições de pesquisa. Sem dúvida a questão ambiental é um desses temas que lançou desafios inadiáveis às áreas de ciência e tecnologia. As discussões sobre preservação de recursos, controle de riscos e formas de precaução redefiniram a agenda dos agentes científicos e tecnológicos (BIN, 2004).

Não é mais possível gerar tecnologias que não atendam a exigências de sustentabilidade ambiental, sob o risco de se gerar embargos, boicotes e mecanismos jurídicos de interdição. As Instituições Públicas de Pesquisa (IPPs) tiveram também que internalizar esse tipo de demandas da sociedade civil, sob risco de verem seus planos de ação questionados em diferentes esferas, como órgãos de proteção ao consumidor, vigilância sanitária, entre outros. A disseminação de formas de certificação ambiental (selos verdes) e outras medidas forçam a internalização dessa temática em diversas instituições e na formulação de suas políticas de avaliação, e entre elas a Embrapa consta como uma que se esforçou por atender a essas prerrogativas (BORGES FILHO, 2005).

Na próxima seção, será debatida a entrada em cena das práticas de avaliação na Embrapa e a importância das variáveis ambientais na construção dos indicadores de impactos tecnológicos.

\section{Avaliação tecnológica na Embrapa}

A Empresa Brasileira de Pesquisa Agropecuária (Embrapa) foi criada em 1973, e desde sua fundação se tornou uma referência no setor agropecuário enquanto instituto público de pesquisa, destinada 


\section{Avaliação de impactos ambientais: redefinindo a inovação tecnológica}

Thales Novaes de Andrade

a sintonizar as novas tendências de modernização agrícola aos padrões internacionais (AGUIAR, 1986).

A criação da Empresa buscava promover a institucionalização da pesquisa agropecuária no Brasil, objetivando a modernização da agricultura nacional e o "repasse" de tecnologias produzidas em países desenvolvidos para serem aproveitadas no país.

A lógica da pesquisa científica e tecnológica era nesse primeiro momento basicamente ofertista, assentada no desenvolvimento de técnicas e inovações específicas que posteriormente deveriam se encaixar nas preferências de usuários, empresas e outros agentes do setor.

Segundo Salles Filho et al. (2000), na década de 1980 a Embrapa iniciará uma nova fase que será caracterizada por uma atenção maior aos vínculos entre os agentes internos e as solicitações mais configuradas do meio agrícola. Para os autores, esse período é importante pois

...a partir de 1985, caracteriza-se pelo ajustamento do modelo institucional, por meio da reorganização as atividades-fim e da busca de maior vinculação dessas às demandas externas (SALLES FILHO et al., 2000, p. 104-5).

A empresa teve que reconfigurar o aparato burocrático-administrativo que norteia as suas atividades, buscando tanto inserir critérios de gerência que interfiram nas metas de pesquisa quanto deixando-a mais aberta às demandas externas.

Assim como outras instituições de pesquisa na área agrícola no Brasil, a Embrapa se situa em uma condição contraditória. Por um lado, ela está inserida em um espaço de grandes avanços tecnológicos, impulsionados por novas interações entre disciplinas científicas antes separadas e por oportunidades comerciais internacionais.

Mas, apesar disso, essas instituições de pesquisa passam a enfrentar nesse período também sérios constrangimentos orçamentários, perda de recursos humanos para a iniciativa privada e sucateamento de infraestrutura (SALLES FILHO et al., 2000). 
É nesse período que se realiza a passagem do modelo ofertista para o modelo de pesquisa por demanda, no qual a Empresa passa a induzir projetos a cientistas e técnicos de acordo com demandas externas (SALLES FILHO et al., 2000).

Devido a isso foram criados novos setores internos responsáveis por garantir o atendimento dessas demandas com vistas à sustentabilidade da Instituição e o alcance de metas previamente definidas. O primeiro passo nesse sentido é a criação dos Planos Diretores da Embrapa (PDEs) que visam propor os princípios que norteiam as atividades desenvolvidas pela Embrapa em determinados períodos de tempo.

O I PDE (1988-92) foi o primeiro documento com este intuito. Ele propunha uma ampla reconfiguração institucional que, nessa época, representará uma profunda mudança nas rotinas de P\&D da Empresa.

Na sequência, e após a elaboração do PDE, o segundo passo foi a reformulação do modelo de pesquisa, o que, de acordo com a visão e a abordagem proposta pela Instituição, permitiria criar condições para um salto qualitativo nas atividades-fim. A criação do Sistema Embrapa de Planejamento (SEP), em 1992, representou uma iniciativa voltada para a operacionalização de um modelo de programação de P\&D conectando o estratégico ao operacional. O estabelecimento de "o que pesquisar e para quem" deveria estar subordinado ao Modelo de Pesquisa por Demanda, sendo esse último o orientador do SEP (SALLES FILHO et al., 2000, p. 111-2).

A articulação da esfera estratégica com a operacional significou um passo importante para o rompimento da total autonomia e possibilidades decisórias dos técnicos e pesquisadores em estabelecerem suas agendas de pesquisa. Isso significou um primeiro passo para uma redefinição das práticas de inovação no interior de um espaço científico avançado.

O II PDE (1994-98) redefine a missão e os objetivos da Empresa, além de determinar as diretrizes e as ações estratégicas que ela deveria adotar (SALLES FILHO et al., 2000). O II PDE é importante por ser o primeiro a mencionar a necessidade de controle das atividades e de avaliação do desempenho da Instituição. 


\section{Avaliação de impactos ambientais: redefinindo a inovação tecnológica}

Thales Novaes de Andrade

Não é mais possível financiar projetos tecnológicos e de inovação sem incorporar metodologias de avaliação que estabeleçam parâmetros de desempenho e eficácia dos projetos. Agentes situados para além do círculo institucional mais próximo podem interferir nos mecanismos de seletividade dos projetos.

A avaliação continuada de programas e a preocupação com os impactos da tecnologias em suas mais diferentes acepções passam a constituir uma necessidade institucional incontornável que solicita um considerável esforço de preparação de quadros e construção de metodologias próprias (FAHRENKROG et al., 2002).

O III PDE (1999-2003),renova o modelo de gestão, estabelecendo mecanismos de controle mais precisos. Comitês técnicos, gestores e consultores ad hoc são solicitados a avaliarem a elaboração e os impactos possíveis dos projetos enviados. O Comitê Gestor da Programação é a instância que decide ao final pela contratação dos projetos e aloca os recursos, a partir da avaliação do chamado "mérito estratégico" dos projetos (BIN, 2004).

Além disso, o III PDE merece especial atenção por inserir a questão ambiental do desenvolvimento sustentável como uma das principais preocupações da Embrapa. A preocupação ambiental deveria estar presente na prática institucional, sendo objeto de gerenciamento da alta administração e objeto de estudo por parte dos pesquisadores. Não por acaso, essa questão também será incorporada pelos mecanismos de avaliação de impactos posteriores. (BIN, 2004; BORGES FILHO, 2005).

No início do novo milênio, a Embrapa prosseguiu no processo de refinamento de seus mecanismos de gerenciamento e planejamento. Segundo Bin,

Em 2002, ocorre a passagem do Sistema Embrapa de Planejamento (SEP) para o Sistema Embrapa de Gestão (SEG), organizado não mais em Programas Nacionais e sim em Macroprogramas (MPs). Com isso foram introduzidos instrumentos para operacionalizar a indução de projetos e a formação de redes e arranjos cooperativos inovadores (por meio de editais), visando incrementar a priorização de atividades de pesquisa (BIN, 2004: 95). 
A indução de projetos passa a ser um elemento essencial e estratégico, legitimado institucionalmente por posições exteriores à própria empresa. Nesse momento, a necessidade de critérios objetivos para a tomada de decisões incentiva a adoção de mecanismos de avaliação de impactos. Diversas subdivisões institucionais serão concebidas com a intenção explícita de avaliar a prática científica e tecnológica da Empresa.

A preocupação com o refinamento da gestão na Embrapa é confirmada com a criação, em 2001, do primeiro documento que trata da questão da avaliação dos impactos tecnológicos de maneira sistematizada e integrada (ÁVILA, 2001). Os atores responsáveis pela avaliação ganham um referencial mais conciso e uniforme para desenvolver esse tipo de atividade na Embrapa. Esses últimos se veem alçados à condição de grupo estratégico para a empresa, portadores de um conhecimento administrativo e gerencial que irá no curto prazo definir hierarquias e novas tensões dentro desse campo.

A questão dos impactos é uma dimensão importante presente a partir do IV PDE, devido à necessidade da avaliação dos resultados de pesquisa e à justificativa do repasse de recursos públicos e privados para as atividades da Instituição (BORGES FILHO, 2005). O IV PDE (2004-2007) demonstra a preocupação em ampliar e fortalecer as bases científicas, promover a inovação tecnológica e os arranjos institucionais adequados para vários níveis de seus objetivos estratégicos (EMBRAPA, 2004).

E uma das áreas que mais investiu na construção de métodos sofisticados de avaliação de projetos foi a de meio ambiente. Na unidade sediada em Jaguariúna (SP), a Embrapa Meio Ambiente, foi desenvolvido o Ambiente-agro, uma ferramenta de Avaliação de Impactos Ambientais de projetos elaborados por técnicos da empresa e aplicados em propriedades rurais.

Segundo a empresa,

O Sistema permite ativa participação dos produtores/responsáveis, e serve para a comunicação e armazenamento das informações sobre impactos ambientais. A plataforma computacional é 


\section{Avaliação de impactos ambientais: redefinindo a inovação tecnológica}

Thales Novaes de Andrade

amplamente disponível, passível de distribuição e uso a baixo custo e permite a emissão direta de relatórios em forma impressa de fácil manuseio.

Pesquisadores do Grupo de Estudos de Organização da Pesquisa e da Inovação (GEOPI), da Unicamp e técnicos da Embrapa estabeleceram uma parceria para definir metodologias de avaliação de impactos de pesquisa, e a dimensão ambiental recebeu especial destaque. Segundo relatório desse trabalho, a avaliação de impactos ambientais pode ser realizada através de diversas metodologias: métodos de avaliação econômica, métodos ecoenergéticos e métodos de multiatributos (FURTADO et al., 2000).

No caso da construção de metodologias de avaliação de impactos ambientais da Embrapa, o método de multiatributos foi considerado o mais indicado, pois através dele é possível

...a comparação das alterações, sejam potenciais ou observáveis, resultantes da implementação da inovação tecnológica, frente à situação de referência... Além disso, permite o tratamento da multiplicidade de parâmetros indicadores ambientais passíveis de consideração, e responde à necessidade de se obter um índice integrado da dimensão ambiental (FURTADO et al., 2000: 25).

Essa perspectiva de se poder produzir continuamente, em um fluxo definido, avaliações de impacto ambiental torna viável o estabelecimento de uma cultura profissional nova e atuante. A busca por índices que sintetizem os impactos ambientais das inovações tecnológicas representa um dos aspectos centrais do estabelecimento dessas metodologias. $\mathrm{O}$ interesse da empresa consiste em aproximar produtores, técnicos e tomadores de decisão sobre as implicações ambientais das atividades tecnológicas, em consonância com tendências verificadas em diferentes países (ÁVILA et al, 2005).

Em 2006, surge uma nova metodologia de referência para a avaliação de impactos tecnológicos na Empresa. O documento produzido por Ávila, Rodrigues \& Vedovoto (2006) trata de quatro dimensões de impactos: econômicos, ambientais, sociais e político-institucionais. 
O avaliador deve selecionar três inovações representativas da prática tecnológica de sua Unidade Descentralizada, e com base na metodologia proposta, avaliar as quatro dimensões no nível da cadeia produtiva.

A avaliação de impactos econômicos tem como objetivo avaliar os incrementos de renda nos vários segmentos de uma cadeia produtiva, para comprovar a rentabilidade advinda de uma inovação tecnológica. $\mathrm{O}$ principal método utilizado é o cálculo de excedente econômico gerado pela inovação tecnológica, tendo em vista ter acesso à Taxa Interna de Retorno (T.I.R.) ou à Relação Benefício/Custo (B/C) (ÁVILA; RODRIGUES; VEDOVOTO, 2006, p. 8-23).

A metodologia Ambitec também é empregada no caso dos impactos ambientais. O objetivo é avaliar os impactos ambientais de inovações tecnológicas geradas/transferidas através da pesquisa da Embrapa, identificando impactos positivos e negativos, municiando ações que visem o desenvolvimento sustentável e a não-agressão do ambiente. $O$ Ambitec-Agro se subdivide em três tipos de localidades: Ambitec-Agricultura, Ambitec-Produção Animal e Ambitec-Agroindústria. Os principais aspectos avaliados são o alcance da tecnologia, a eficiência tecnológica e a conservação ambiental, além de variáveis específicas de cada um dos três instrumentos (ÁVILA, RODRIGUES \& VEDOVOTO, 2006, p. 48-59).

Essas ferramentas têm sido utilizadas para os relatórios anuais da Embrapa de forma a subsidiar as instâncias administrativas a alocarem recursos e priorizarem áreas e formas de intervenção tidas como estratégicas pela empresa. No próximo item será discutido o impacto dessas ferramentas na prática de inovação conduzida pelos técnicos cujos projetos têm sido avaliados pelo sistema AMBITEC.

\section{A avaliação de impactos ambientais: a visão interna do campo}

Como foi visto acima, nos últimos anos os pesquisadores da Embrapa precisam atender a uma série de novas exigências 


\section{Avaliação de impactos ambientais: redefinindo a inovação tecnológica}

Thales Novaes de Andrade

institucionais tendo em vista o aperfeiçoamento gerencial das atividades de pesquisa e inovação da empresa.

Os processos de avaliação de impactos das tecnologias empregadas e o emprego de metodologias e elaboração de coeficientes adentraram na agenda de administradores científicos, policy makers e pesquisadores, tanto os seniors como os novos que foram admitidos recentemente.

Segundo Bourdieu (2004), todo campo científico é atravessado por um conjunto de tensões na medida em que os agentes pretendem aumentar seu capital institucional recrutando aliados e estabelecendo diretrizes que atendem a seus interesses. A Embrapa pode ser vista como um campo em que os diferentes setores pretendem implementar regras e mecanismos para validar suas posições. A perspectiva do presente estudo é que a avaliação de impactos ambientais também implica em uma redefinição de procedimentos que levam a novas configurações de poder no interior do campo.

Será discutido o processo de implementação desses procedimentos de gerenciamento tecnológico, com suas promessas e tensões internas ao campo. Inicialmente será tratada a implantação do Sistema Ambitec, que teve profundos impactos nas formas de organização da pesquisa na empresa.

\section{A implantação do Ambitec: metas e tensões}

É possível perceber que a utilização de ferramentas de avaliação de inovações tecnológicas, como o AMBITEC, tem um profundo respaldo em termos institucionais, e a empresa procurou reforçar essa expectativa por intermédio de uma série de publicações internas e externas (MONTEIRO; RODRIGUES, 2006; IRIAS et al., 2004).

Mas o processo de consolidação dessas práticas de gestão junto ao universo de técnicos, pesquisadores e usuários não ocorreu totalmente sem tensões. Ao tomarmos contato com a prática 
dos pesquisadores que implementam projetos de inovação no setor agropecuário, é possível perceber que ocorreu uma certa resistência no período inicial de estabelecimento dessas ferramentas de avaliação.

Os profissionais encarregados de calcular a Taxa Interna de Retorno viam o estabelecimento dessas rotinas como um fardo a mais, que representaria um acúmulo de atividades que não agregaria conhecimento adicional relevante. Segundo um dos pesquisadores da empresa,

É lógico que esse tipo de movimento engendre um determinado nível de resistência nas equipes. No início a resistência foi razoavelmente grande porque acontece o seguinte: a Embrapa tem uma experiência de muito longa data, inclusive uma certa liderança na literatura de avaliação de impacto econômico, taxa interna de retorno, tem toda uma equipe bem consolidada e uma visibilidade na literatura internacional nessa parte de avaliação de impacto, em termos de taxa interna de retorno, parte econômica. A parte social e ambiental é bem mais recente. E como já havia a prática de avaliações dessa parte econômica, era natural que os pesquisadores que são denominados como aqueles de socioeconomia das unidades fossem a linha de frente dessas avaliações, isso caiu sobre eles como uma responsabilidade a mais, tinha uma linha de pensamento, uma temática de pesquisa ambiental especialmente, social nem tanto, que não era da especialidade deles, e já chegando com uma mecânica de avaliação que aparecia vindo da sede como a imposição de uma nova função... então gerou mesmo uma certa resistência no começo.

(Técnico1)

O acúmulo e duplicação das atribuições dos técnicos e avaliadores é sentido como algo que pode tornar problemática a participação desses agentes nas atividades de avaliação.

É possível perceber uma ausência de envolvimento inicial de boa parte dos pesquisadores com essas novas ferramentas gerenciais em boa parte explicável pelo acúmulo de responsabilidades dos pesquisadores e pela falta de clareza dos rumos desses empreendimentos gerenciais. 


\section{Avaliação de impactos ambientais: redefinindo a inovação tecnológica}

Thales Novaes de Andrade

A cultura institucional que se instala na empresa é em boa parte responsável por uma sensação de acúmulo de exigências e falta de espaço de negociações com as instâncias mais altas da Empresa.

Um documento interno da Embrapa Pecuária Sudeste (PRIMAVESI, 2006), apresenta dados que atestam as dificuldades que a empresa vem enfrentando na busca de adesão de seus funcionários aos projetos de avaliação de impactos. Boa parte dos pesquisadores desta unidade não estão plenamente cientes da importância da aplicação dessas ferramentas e nem se sentem instados a participar do processo.

Segundo levantamento junto a diversos pesquisadores da unidade, inicialmente muitos deles desconheciam os procedimentos de avaliação de impactos desenvolvidos em suas próprias unidades (PRIMAVESI, 2006: 20). Essa mesma tendência foi verificada junto aos presidentes de Comitês Técnicos Internos (CTIs) de outras unidades da Empresa, o que atesta uma dificuldade inicial em se angariar adesão junto às diferentes instâncias da instituição.

Após a realização de encontros e seminários internos, foi detectada uma alteração quantitativa e qualitativa da postura dos pesquisadores, indicando uma tendência de envolvimento com essas práticas de gerenciamento e afinação com as metas da empresa.

Mas à medida que os resultados práticos foram aparecendo, o instrumento de avaliação se mostrou eficaz e simples, e a preocupação ambiental entrou fortemente na agenda da empresa.

Outro foco de tensões presente na empresa frente às práticas de avaliação está relacionado à diferenciação entre Produtos e Processos da prática tecnológica. Diversas unidades da Embrapa se caracterizam por desenvolverem preferencialmente produtos agropecuários (variedades de sementes etc.), enquanto que outras se direcionam mais para processos (manejo, irrigação).

De acordo com um pesquisador da Embrapa Sudeste, cujo foco principal é o desenvolvimento de processos, essa problemática não está bem resolvida a partir das novas fórmulas de gestão. Segundo ele, 
“...na nossa unidade, a maior parte das pesquisas que são geradas estão ligadas a processos e não a produto. Então por ex. na Embrapa tal é milho sorgo, eles tem um indicador novas variedades de milho. Então eles fazem aprimoramento genético do milho, detectam problemas e lançam uma variedade. Aí se avalia o lançamento de uma variedade, é fácil, você quantifica para quantos vendeu. E processo? Por ex. manejo de pastagem, melhoramos esse manejo. Tem que transferir esse processo, mas como fazer? Como transfere esse processo? Essa transferência depende de você treinar alguém para utilizar essa ferramenta e você avaliar. Software é produto, algo fácil de avaliar, usou, serviu ou não.O usuário é visível. No caso de processo tem o usuário em potencial. Para realizar isso tem que treinar ele. Tem uma preparação nos processos que o produto não envolve. E isso leva tempo. Como avaliar um processo se eu não treinei ninguém?"

(Técnico 2)

O pressuposto das ferramentas de avaliação de impactos é basicamente o desenvolvimento de produtos. Esse aspecto é paradoxal, pois a literatura da área de gestão aponta um imbricamento constante entre inovações tecnológicas e inovações organizacionais, em que não seria mais possível diferenciar produtos técnicos e tecnologias de processo (SANIDAS, 2004).

Esse autor ressalta ainda que as inovações tecnológicas por si só não são capazes de aprimorar a produtividade, elas dependem do suporte das organizacionais para funcionarem de maneira apropriada dentro da produção industrial. Os níveis de competitividade econômica das empresas não seriam dados pelos seus resultados de $\mathrm{P} \& \mathrm{D}$, mas sim no modo como esses resultados são administrados pelas inovações organizacionais.

Observando a implementação das ferramentas de avaliação de impactos ambientais, pode ser percebido que produtos e processos em realidade continuam sendo elementos que se distanciam, são difíceis de compatibilizar. A tendência observada é que relatórios de produtos e de avaliação de processos apresentam tipos de resultados e configuração distintas. 


\section{Avaliação de impactos ambientais: redefinindo a inovação tecnológica}

Thales Novaes de Andrade

“...como a Embrapa, assim como os institutos internacionais sempre tiveram recursos genéticos e tecnologias de insumos, então esses são os tipos de tecnologias evidentes. Se você no campo aplica mais adubo, terá resposta clara, e você compara com outros ativos, e acabou o problema. Enquanto que outras tecnologias têm implicações muito mais complexas. Isso faz com que a geração daqueles relatórios tenha, em termos da qualidade das informações, tenha essa diferença. Para quem tem uma tecnologia de tipo mais convencional é fácil espelhar aquilo em termos de relatório, enquanto que outros, que são tecnologias com mais correlações, essas acabam por receber relatórios que são mais especulativos às vezes..."

(Técnico 1)

Unidades de processos e de produtos enfrentam desafios diferenciados no momento de se submeterem a essas fórmulas de avaliação de impactos ambientais. Isso implica que a universalização dos procedimentos de avaliação precisa ser compensada com um peso diferenciado de fórmulas de recompensas e punições da parte dos administradores científicos, o que em muitos momentos gera outras discordâncias.

Por outro lado, a entrada em cena das avaliações de impacto ambiental irá gerar um outro tipo de tensão entre os pesquisadores que trabalham com produtos e processos tecnológicos, e que coloca em foco os pressupostos das ferramentas de avaliação.

Geralmente, pesquisas que lidam com produtos têm efeitos econômicos positivos mas impactos ambientais negativos. Por exemplo, uma variedade de semente pode trazer bons indicadores econômicos em termos de rentabilidade e diminuição de ciclos de produtividade, mas também efeitos ambientais perversos na forma de saturação do ecossistema por intermédio da utilização de defensivos.

Por outro lado, tecnologias de manejo não trazem resultados econômicos imediatos, os indicadores de produtividade não são significativos, mas os impactos ambientais são baixos (ÁVILA et al., 2005).

Isso tem gerado desconfortos entre os dois grupos de pesquisadores, que começam a pedir parâmetros específicos de avaliação. 
Segundo um dos técnicos entrevistados, existem sinais recentes dessas tensões, que colocam em evidência o problema da implementação de um sistema único de avaliação de inovação tecnológica. Segundo ele, é possível perceber

uma certa frustração por parte de grande número de pesquisadores, em especial aqueles que trabalham com tecnologias mais convencionais...em geral, aquelas tecnologias de manejo e de gestão tendem a gerar impactos mais positivos com amplitude maior, especialmente os impactos ambientais. Já por outro lado aquelas tecnologias mais convencionais, sementes melhoradas, insumos, sistema de produção para novas áreas (algodão para o cerrado, coisa assim) tendem a gerar impactos mais negativos, porque são em essência tecnologias de intensificação agropecuária, então você intensifica portanto tem mais demanda por insumos, o que é um impacto ecológico negativo, sem dúvida nenhuma. Você tem mais demanda por recursos naturais que também é um impacto negativo, mais potencial de emissão de poluentes para o meio, mais pressão sobre a biodiversidade etc...os índices são negativos do ponto de vista ecológico. Por outro lado, essa intensificação que gerou impactos negativos de pressão sobre o ambiente resultou em grande melhoria nos aspectos de renda, qualidade de emprego, demanda por oportunidades de trabalho...

(Técnico 3)

Essa tensão se explica porque a utilização das ferramentas tem por pressuposto que os pesquisadores precisam atender a diversos indicadores simultaneamente, o que pode gerar ganhos institucionais mas perdas organizacionais.

Essa diferenciação entre produtos e processos permite observar um aspecto relevante da nova lógica inovativa. Em grande medida, o pressuposto das ferramentas de avaliação é basicamente o desenvolvimento e aprimoramento de produtos. Esse aspecto é paradoxal, pois a literatura da área de gestão aponta um imbricamento constante entre inovações tecnológicas e inovações organizacionais, em que não seria mais possível diferenciar produtos técnicos e tecnologias de processos (SNIDAS, 2004). 


\section{Avaliação de impactos ambientais: redefinindo a inovação tecnológica}

Thales Novaes de Andrade

Esse autor ressalta que as inovações tecnológicas por si só não são capazes de aprimorar a produtividade, elas dependem do suporte das organizacionais para funcionarem de maneira apropriada dentro da produção industrial. Os níveis de competitividade econômica das empresas não seriam dados pelos seus resultados de $\mathrm{P} \& \mathrm{D}$, mas sim no modo como esses resultados são administrados pelas inovações organizacionais.

Para sanear esses desconfortos, tem sido utilizada a estratégia de se eleger índices agregados. Com isso é possível diluir o desconforto internalizando os índices na ferramenta e agregando-os, dessa forma as implicações ambientais e econômicas se misturam e elevam os indicadores.

O índice agregado traz uma vantagem que é ter o resultado final integrado, mas traz a desvantagem que esconde tudo que está por trás... se você olhar só o índice final e não se atentar para o conteúdo daquele índice, você corre o risco de interpretações extremamente inadequadas inclusive...

(Técnico 3 )

A fala do pesquisador aponta para uma tensão interessante entre o índice e seu conteúdo qualitativo. Nesse contexto, entre a preocupação ambiental e econômica situa-se o indicador numérico que algumas vezes mais oculta do que mostra em termos de viabilidade tecnológica.

Outro pesquisador exprime esse problema em outros termos. De origem mais recente na instituição, ele detecta que a avaliação de impactos busca atingir uma média de procedimentos nas formas de avaliação. É preciso uniformizar práticas e estilos de se conduzir a inovação tecnológica, e essas ferramentas viabilizam esse empreendimento, que é ao mesmo tempo técnico, científico e administrativo.

O pessoal está se acostumando com a avaliação ex-ante, apontar os impactos esperados...no caso de variedades é mais fácil, mas com outras tecnologias é preciso adaptar...os índices acabam sendo mais uma aproximação, um indicativo...

(Técnico 4) 
A necessidade de homogeneizar os índices revela claramente que é necessário levar em conta o conjunto de tecnologias para se criar médias e aproximações.

À medida que os pesquisadores sentem necessidade de apontar aspectos específicos de suas tecnologias, os relatórios passam a incorporar descrições mais especializadas. Estas, apesar de relevantes, estão fora dos índices e, portanto, têm um peso pouco significativo na avaliação. Certas apreciações importantes são acrescidas na forma de comentários que, contudo, não são devidamente contabilizados no coeficiente final.

A questão da multifuncionalidade também é um aspecto relevante na discussão sobre a especificidade tecnológica. Ao buscar um padrão médio de avaliação da inovação tecnológica, perde-se a oportunidade de se pensar os diversos modos de aproveitamento possível de uma tecnologia.

Uma inovação pode ser relevante por sua variabilidade e reversibilidade, por formas múltiplas de inserção em seu entorno. Mas como dimensionar isso pelas ferramentas de avaliação vigentes?

Um dos técnicos entrevistados expôs essa questão nos seguintes termos: muitas vezes a inovação fica presa à questão agrícola, mas, por exemplo, no caso de um motor multicombustível, ele poderia servir para camping, gerar eletricidade em outras situações, geradores etc. As inovações partem do ambiente agrícola mas podem expandir sua influência para outras áreas.

Mas ocorre que esse aspecto não pode ser levado em conta em suas avaliações de impacto, uma vez que os indicadores selecionados já são preestabelecidos. Isso significa que as avaliações muitas vezes subdimensionam os impactos da tecnologia, restringem os objetos à sua funcionalidade restrita e convencionada. $\mathrm{O}$ objeto técnico é ossificado pelos diferentes indicadores, não podendo ser concebido fora dos parâmetros pré-concebidos.

As manifestações dos pesquisadores apontam para diversos aspectos que indicam transformações na prática de inovação tecnológica e a presença de tensões no interior do campo. Este vem 


\section{Avaliação de impactos ambientais: redefinindo a inovação tecnológica}

Thales Novaes de Andrade

sendo controlado por uma lógica gerencial que é responsável por transformações no sentido que a tecnologia se reveste dentro dos espaços institucionalizados de pesquisa.

A percepção de Bourdieu sobre essas novas tendências de avaliação da prática científica é interessante, pois indica um conjunto de incertezas que marcam o campo. Para ele, a probabilidade da administração científica conseguir realizar uma real mediação entre o capital científico puro e o institucionalizado no interior do campo científico é algo absolutamente incerto e variável.

Se penso que medidas administrativas visando melhorar a avaliação da pesquisa e colocar em prática um sistema de sanções... próprias para favorecer as melhores pesquisas e os melhores pesquisadores seriam as mais ineficazes e teriam como efeito, mais provavelmente, favorecer ou reforçar as disfunções que supostamente deveriam ser reduzidas, é porque tenho sérias dúvidas e seriamente fundadas sobre a capacidade das instâncias administrativas para produzirem avaliações realmente objetivas e inspiradas" (BOURDIEU, 2004: 62-3).

Essa discussão tem sofrido uma série de resistências da parte da sociologia construtivista e contextual da ciência e das técnicas. Segundo essa linha de pensamento, que desde os anos 80 vem redefinindo a discussão sobre autonomia científica, a relação entre técnicos e pesquisadores com outros campos é muito mais complexa.

Para Knorr-Cetina (2005), não faz sentido mais discutir a autonomia dos agentes técnicos e científicos uma vez que estes estão incorporados em campos transcientíficos compostos de lógicas as mais diversas. Existem relações de recursos, segundo os termos de Knorr Cetina, que exigem um imbricamento contextual em que alunos e orientadores, técnicos e gerentes estabelecem acordos ora de conflito, ora de cooperação, em que a lógica do campo científico precisa estabelecer analogias e aproximações com outras formas de pensamento.

A dinâmica da produção de conhecimento transcende a noção de campo científico ou comunidade científica, uma vez que se faz necessário lidar com perspectivas econômicas, políticas e 
linguísticas diversas. Então a prática científica não carece de autonomia, mas sim está envolvida em uma rede múltipla de causalidades, campos transcientíficos variáveis, que “...nos remetem a redes de relações simbólicas que em princípio transcendem os limites de uma comunidade científica ou campo científico em suas amplas definições" (KNORR-CETINA, 2005: 204).

A inserção da avaliação de impactos ambientais nas ferramentas utilizadas pela Embrapa constitui um aspecto delicado para a área científica, de modo que muitas tensões podem daí emergir. Apesar da área ambiental ser levada em consideração nessas práticas avaliativas, sua inserção precisa ser melhor matizada.

\section{Conclusão}

Os estudos sociais da Ciência e da Tecnologia estão cada vez mais atentos às interferências que as instituições de pesquisa infligem às atividades inovativas. A inserção das variáveis ambientais nas práticas de avaliação de impactos tecnológicos propiciou novas perspectivas de gerenciamento de ciência e tecnologia e solicitou comportamentos e condutas institucionais antes inexistentes. A formação de indicadores específicos e o cruzamento de informações sobre uso de insumos, áreas de cultivo trouxe abordagens novas que redefinem os parâmetros de produtividade e sustentabilidade.

Ao examinarmos os rumos do gerenciamento tecnológico na Embrapa, é possível perceber que a realização técnica e a prática inovativa requereram o atendimento a uma variedade de parâmetros e condicionantes.

Apesar de imperar consenso sobre a importância e necessidade das variáveis ambientais nas práticas de avaliação de tecnologias, esse não é um tema isento de dificuldades e conflitos de interesses. As tensões recorrentes entre intensificação agrícola e aprimoramento de recursos, e entre produtos e processos da atividade agropecuária, mostram que o estabelecimento de indicadores 
Avaliação de impactos ambientais: redefinindo a inovação tecnológica

Thales Novaes de Andrade

e variáveis por si só não garante o atendimento aos interesses ambientais.

A construção de metodologias de avaliação enfrenta uma série de dificuldades que a análise sociológica pode colaborar para apontar os caminhos e problemas e a pensar como o campo científico se redefine a partir dessas transformações técnicas e organizacionais.

Original recebido em: 22/11/2011 Versão final recebida em: 16/03/2012

\section{Referências}

ÁGUIAR, R. C. Abrindo o pacote tecnológico: Estado e pesquisa agropecuária no Brasil. São Paulo: Polis/CNPq, 1986.

ÁVILA, A. F. Avaliação dos impactos econômicos, sociais e ambientais da pesquisa da Embrapa: Metodologia de Referência. Brasília: Embrapa/SEA, 2001.

ÁVILA, A. F.; MAGALHÃES, M. C.; VEDOVOTO, G.; IRIAS, L. J.; RODRIGUES, G. S. Impactos econômicos, sociais e ambientais dos investimentos na Embrapa, Revista de Política Agrícola, ano XIV, n. 4, out. /nov. /dez. 2005.

ÁVILA, A. F.; RODRIGUES, G. S. \& VEDOVOTO, G. L. Avaliação dos impactos de tecnologias geradas pela Embrapa: Metodologia de Referência. Brasília: Embrapa/SGE, 2006.

BECK, U. Risk Society, London, Sage, 1992.

BIN, A. Agricultura e meio ambiente: contexto e iniciativas da pesquisa pública. Dissertação (Mestrado em Política Científica e Tecnológica) - Instituto de Geociências, Unicamp, Campinas, 2004.

BORGES FILHO, E. L. Da redução de insumos agrícolas à agroecologia: a trajetória das pesquisas com práticas agrícolas mais ecológicas na Embrapa. Tese (Doutorado em Economia) Instituto de Economia, Unicamp, Campinas, 2005. 
BOURDIEU, P. Os usos sociais da ciência: por uma sociologia clínica do campo científico. São Paulo: Unesp, 2004.

CALLON, M. et al. La gestion stratégique de la recherche et de la technologie: l'évaluaton des programmes. Paris: Economica, 1995. CASSIOLATO, J. E. \& LASTRES, H. Sistemas de Inovação: Políticas e Perspectivas. Parcerias estratégicas, Brasília, n. 08, 2000, p. 237-255.

DAGNINO, R. Ciência e tecnologia no Brasil: o processo decisório e a comunidade de pesquisa. Campinas: Unicamp, 2007.

EMBRAPA. Secretaria de Administração e Estratégia. IV Plano Diretor da Embrapa: 2004-2007. Brasília: Embrapa, 2004.

FAHRENKROG, G. et al. RTD Evaluation Toolbox - Assessing the SocioEconomic Impact of RTD-Policies, IPTS Technical Report Series, 2002.

FREEMAN, C. La teoria económica de la innovación industrial. Madrid: Alianza Editorial, 1975.

IRIAS, L.J. et al. Avaliação de impacto ambiental de inovação tecnológica agropecuária - aplicação do sistema Ambitec. Agricultura em São Paulo, São Paulo, v. 51, n. 1, 2004, 23-39.

KNORR-CETINA, K. La fabricacion del conocimiento, Bernal, Un. Quilmes, 2005.

MONTEIRO, R.C. \& RODRIGUES, G.S. A system of integrated indicators for socio-environmental assessment and ecocertification in agriculture - AMBITEC-AGRO. Journal of technology management and innovation, v. 1, n. 3, 2006, p. 47-59.

PRIMAVESI, O. et al. Análise e melhoria de processo: avaliação dos impactos econômicos, sociais e ambientais de tecnologias da Embrapa Pecuária Sudeste, Embrapa Pecuária Sudeste, Documentos 53, 2006.

SALLES FILHO, S. et al.Ciência, tecnologia e inovação: a reorganização da pesquisa pública no Brasil. Campinas: Komedi, 2000. 


\section{Avaliação de impactos ambientais: redefinindo a inovação tecnológica}

Thales Novaes de Andrade

SANIDAS, E. Technology, technical and organizational innovations, economic and societal growth. Technology in Society, v. 26, n. 1, p. 67-84, 2004.

TRIGUEIRO, M. G. O clone de Prometeu. Brasília: UnB, 2002.

ZACKIEWICZ, M. Coordenação e organização da inovação: perspectivas do estudo do futuro e da avaliação em ciência e tecnologia. Parcerias estratégicas, Brasília, n. 17, 2003, p. 193-214.

\section{Abstract \\ Environmental impacts assessment: reshaping technological innovation}

Technological innovation contains a sophisticated management background, and scientific managers must integrate different research and development fields. Impacts assessment becomes even more relevant in many research institutions, leading projects budget and implementation. In such context, environmental aspects are considered extremely relevant, and their impacts must be taken into account in technological assessments.

Keywords: technological innovation, impacts assessment, environment, Embrapa. 